\title{
Qualitative assessment framework to evaluate sustainability indicators affecting infrastructure construction projects in developing countries using the Analytical Hierarchy Process (AHP)
}

\author{
A. M. Aboushady ${ }^{1}$ \& S. A. R. El-Sawy ${ }^{2}$ \\ ${ }^{1}$ Structural Engineering Department, Faculty of Engineering, \\ Cairo University, Egypt \\ ${ }^{2}$ Middle Eastern Studies Department, Girls' College, \\ Dammam, Kingdom of Saudi Arabia
}

\begin{abstract}
There are different sustainability indicators that may affect the construction projects which are necessary to be identified in order to improve the construction industry. This paper proposes a qualitative assessment framework that can assist construction project teams with a useful tool to identify and prioritize sustainability indicators impacting their projects. First, a literature review is conducted to identify the sustainability indicators that need to be considered in achieving a more sustainable construction project in Egypt. The factors are then ranked through a survey questionnaire and experts' judgment using a 7-point Likert scale to identify the most significant factors. The AHP is used in this paper to determine experts' importance weights. A case study of an infrastructure project in Egypt is conducted to identify, and prioritize different sustainability indicators affecting the construction of infrastructure projects in Egypt. The consent of framework development can be generalized and applied to other countries by changing related sustainability indicators and expert opinions. The framework solves a major problem that faces infrastructure construction project teams who want to Prioritize and assess quantitatively sustainability indicators existed in their projects prior to the start of construction phase.

Keywords: sustainable construction projects, identification, classification, project management, and prioritization.
\end{abstract}




\section{Introduction}

The construction industry plays an essential rule in the economic prosperity of any society. Sustainable outcomes will result from good site management to encourage resource efficiency, increase materials recovery and avoid disposal costs. Sustainable Construction should not be seen as something that is exclusive to expensive projects, as it has the potential to be applied to any development. According to Walsh [1], the 1998 European Charter on Sustainable Design \& Construction has placed special emphasis on implementation through informed use of construction related sustainability performance indicators, which is setting targets and monitoring real performance in the built environment, which includes buildings, civil engineering projects, transport, service support systems, and infrastructure. As Fernández-Sánchez and Rodríguez-López [2] illustrated that the term sustainable construction has been focused intensively on buildings, but now the sustainability objectives have been introduced to all sectors of civil engineering projects. Also, Zhang et al. [3] illustrated that the construction sector is moving towards an increase in the use of sustainable principles and objectives. According to Herrera and Herrera-Viedma [4], "those individuals (experts or decision-makers) are called on to express their opinions on a predetermined set of alternatives in order to select the best one(s)". Elbarkouky and Fayek [5] defined several elements that may cause expert' judgment to be different, such as academic experience, professional experience, position in their companies, the diversity of such experience, and willingness to provide information or data. Thus, the quality of experts is an essential factor in aggregating their opinions to make sure that their opinions are not flawed (Herrera et al. [6]). This is why there is a high demand to determine the importance weights of experts in deciding on their qualifications prior to evaluating sustainability indicators. Most often, civil project teams have difficulty in evaluating sustainability objectives encountered in their projects, while civil construction firms depend on expert judgment in assessing these sustainability indicators (Zabaal [7]). According to Elbarkouky and Fayek [5], the two main issues that may affect the decisionmaking process are "extracting meaningful data from a group of experts, and combining the experts, subject opinions by resolving disagreements." This is the reason why there is a need to develop a framework to aggregate experts' opinions in prioritizing sustainability indicators that can motivate expert judgment and deal with its relative vagueness and imprecision, linguistically. Thus, there is a need to develop a framework that identifies and qualifies the sustainable indicators that may affect the construction of civil projects.

\section{Literature review}

Sustainable development principles have been implemented in various sectors including the construction industry since it was published in the Brundland Commission Report in 1987. Since then different researchers have tackled the issue of sustainability. Fernández-Sánchez and Rodríguez-López [2] proposed a framework to assess the sustainability indicators linguistically with a special 
emphasis on infrastructure projects in Spain. Li et al. [8] proposed a framework to measure quantitatively the overall sustainability performance of manufacturing companies. Kajikawa et al. [9] developed an analysis model that highlights the benefits, limitations, and future directions of building environment assessment framework of building environment assessment framework and their implications for sustainability indicators. Munier [10] proposed a methodology to select a set of urban sustainability indicators to measure the state of the city, and performance assessment. Gomez-Limon and Riesgo [11] proposed alternative approach to the construction of a composite indicator of agriculture sustainability in Spain. Xing et al. [12] developed a framework model to assess sustainability impact on urban development. Azapagic [13] developed a framework for sustainable development indicators for mining and mineral industry. Dasgupta and Tam [14] developed a framework for assessing sustainability indicators for infrastructure projects. Finally, San-Jose et al. [15] proposed a framework to assess, and analyze environmental sustainability indicators in industrial building projects. All the above researchers did not develop a framework that deals with the qualitative assessment of sustainability indicators in infrastructure in Egypt. Therefore, the qualitative assessment framework was developed in this paper to overcome this limitation and provide recommendation not only applicable to Egypt, but also to any other developing country.

\section{Objectives}

The main objective of this paper is to prioritize critical sustainability indicators affecting infrastructure projects in Egypt. This is achieved through the development of the qualitative sustainability assessment framework. The consent of framework can be generalized and applied to other countries by changing related sustainability indicators and expert opinions. The framework solves a major problem that faces infrastructure project teams who want to prioritize critical indicators affecting their projects in order to produce a list of prioritized sustainability indicators.

\section{Methodology and model development}

The proposed framework is composed of six stages: Identifying critical sustainability indicators, creating Linguistic Scale to rate different critical indicators ,and collecting experts' opinions, applying the Analytical Hierarchy Process (AHP) to determine the experts' importance weights, performing statistical analysis, assessing the Relative Importance Index (RII) for prioritization, and conducting a case study in Egypt as per in figure 1.

\subsection{Identifying critical sustainability development factors}

Critical sustainability indicators were determined using literature review and interviews with thirty experts each of them had twenty years of experience in 
infrastructure projects. Experts agreed that the sustainability indicators can be divided into six groups: Environmental, Social, Economical, Bureaucratic, Construction, and Risk Indicators (Table 1).

\subsection{Creating linguistic scale to rate different critical sustainability indicators and collect experts' opinions}

In this step, a survey-based questionnaire was designed to assist experts in ranking critical sustainability indicators based on the impact of these sustainability indicators on the infrastructure development projects, using a seven-point Likert scale (Saaty [21]), where (1) means Extremely Very Low, (2) means Very Low, (3) means Low, (4) means Medium, (5) means High, (6) means Very High, and (7) means Extremely Very High. Moreover, the questionnaire included a section that contained experts' demographic information that defined five qualification criteria of experts: Q1: Years of experience in Sustainability, Q2: Years of experience in infrastructure projects, Q3: Role in Company, Q4: Diversity of Experience and Q5: Academic record. The key experts also assigned subjective weights $(g)$ to the attributes of each quality criterion that ranged between 0 and 1 , as illustrated in brackets in Table 2. The subjective weight $(g)$ determines the significance of each attribute in computing the relative importance weight factor of each expert. Table 3 lists experts' qualifications and their attributes.

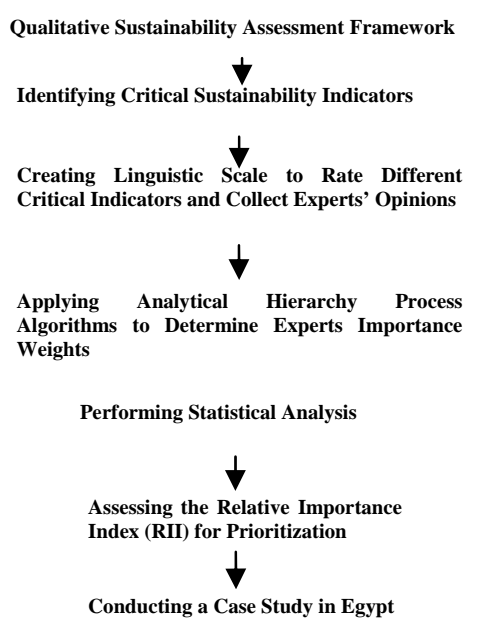

Figure 1: $\quad$ Methodology and model development.

\subsection{Applying Analytical Hierarchy Process Algorithms}

The Analytical Hierarchical Process (AHP) in a multi criteria decision making process (Saaty [16]) was utilized in this step to prioritize sustainability indicators, based on computing the average rating of twenty five experts 
participated in the process of decision-making. The AHP approach was applied because of its simplicity and ability to provide subjective and objective assessments of multiple factors (Elbarkouky et al. [17]). Five human resource managers working in five different construction companies in Egypt, each of them has more than twenty years of experience in human resource, assisted in conducting the pair-wise comparison method to determine the relative importance weight $\left(\mathrm{r}_{\mathrm{k}}\right)$ of each of the five qualification criteria. A five point rating scale was introduced to experts to rank the factors relative to each other, using a standard preference matrix. The cardinality values of the scale ranged between (1) Equal Preference, and (5) Extremely Preferred. The terms: (2) Slightly Preferred, (3) Preferred, and (4) Very Much Preferred were used as intermediate values (Elbarkouky et al. [17]). Table 4 illustrates the values computed using the $\mathrm{n}^{\text {th }}$ root method (Saaty [16]) that has been used to compute the eigenvector elements of the matrix that represents the average ratings of the five human resource managers, where $n$ is the number of rows or columns of the matrix

Table 1: Critical sustainability indicators and their groups.

\begin{tabular}{|c|c|c|c|}
\hline \multicolumn{2}{|r|}{ Group (1):Environmental Indicators } & \multicolumn{2}{|c|}{ Group (3): Economy Indicators } \\
\hline 1 & Energy Consumption & 19 & Life Cycle Cost \\
\hline 2 & Waste Management & 20 & Economical Cost and Benefit \\
\hline 3 & Ecological Footprint & 21 & $\begin{array}{c}\text { Cost Incurred to Users } \\
\text { (Maintenance and Usage Cost) }\end{array}$ \\
\hline 4 & CO2 Emissions & 22 & $\begin{array}{l}\text { Increase in Economic Value of } \\
\text { Environment }\end{array}$ \\
\hline 5 & Noise Pollution & \multicolumn{2}{|c|}{ Group (4): Bureaucratic Indicators } \\
\hline 6 & Material Consumption & 23 & $\begin{array}{l}\text { Project Governance and Strategic } \\
\text { Management }\end{array}$ \\
\hline 7 & Renewable Energy Use & 24 & Improper Project Management \\
\hline 8 & Water Resource Protection & 25 & $\begin{array}{c}\text { Product Warranties, Installation } \\
\text { and Set }\end{array}$ \\
\hline 9 & Barrier Effect of the Project & 26 & Types of Contracts \\
\hline 10 & Use of Regional Materials & \multicolumn{2}{|c|}{ Group (5):Construction Indicators } \\
\hline 11 & Biodiversity Protection & 27 & Design for Disassembly \\
\hline & Group (2): Social Indicators & 28 & Innovative Construction Methods \\
\hline 12 & Safety and Health of Workers & 29 & $\begin{array}{c}\text { Increase in Environmental } \\
\text { Management Accreditation }\end{array}$ \\
\hline 13 & $\begin{array}{c}\text { Necessity of Work and Emergency of } \\
\text { Work }\end{array}$ & 30 & $\begin{array}{c}\text { Increase in Quality Management } \\
\text { Accreditation } \\
\end{array}$ \\
\hline 14 & Project Declaration of General Interest & 31 & Synergies with Other Projects \\
\hline 15 & $\begin{array}{l}\text { Public Participation and Control on the } \\
\text { Project }\end{array}$ & 32 & Plan Maintenance \\
\hline 16 & Accessibility for Human Biodiversity & \multicolumn{2}{|r|}{ Group (6): Risk Indicators } \\
\hline 17 & Respect for Local Customs & 33 & $\begin{array}{l}\text { Mitigating the Effects of Floods } \\
\text { and Quakes }\end{array}$ \\
\hline 18 & $\begin{array}{l}\text { Raising Levels of Training and } \\
\text { Information }\end{array}$ & 34 & $\begin{array}{l}\text { Adaptation and Vulnerability to } \\
\text { Climatic Change }\end{array}$ \\
\hline
\end{tabular}


Table 2: Experts' determination of qualifications criteria and their respective weights.

\begin{tabular}{|c|c|c|c|c|}
\hline $\begin{array}{c}\text { Q1: Years of } \\
\text { Experience in } \\
\text { Sustainability }\end{array}$ & $\begin{array}{c}\text { Q2: Years of } \\
\text { Experience in } \\
\text { Infrastructure } \\
\text { Projects }\end{array}$ & $\begin{array}{c}\text { Q3: Role in } \\
\text { Company }\end{array}$ & $\begin{array}{c}\text { Q4:Diversity } \\
\text { of } \\
\text { Experience }\end{array}$ & $\begin{array}{c}\text { Q5:Academic } \\
\text { Record }\end{array}$ \\
\hline $\begin{array}{c}\text { Less than } 1 \\
\text { year(0.2) }\end{array}$ & $\begin{array}{c}\text { Less than 1 year } \\
(0.2)\end{array}$ & $\begin{array}{c}\text { Site Engineer } \\
(0.2)\end{array}$ & $\begin{array}{c}\text { Very High } \\
(1.0)\end{array}$ & Ph.D (1.0) \\
\hline 1-5 years(0.4) & $1-5$ years(0.4) & $\begin{array}{c}\text { Senior Engineer } \\
(0.4)\end{array}$ & High(0.8) & Master(0.6) \\
\hline 6-10 Years(0.6) & 6-10 Years(0.6) & $\begin{array}{c}\text { Project } \\
\text { Manager (0.6) }\end{array}$ & Medium(0.6) & Bachelor (0.4) \\
\hline 11-15 Years(0.8) & $11-15$ Years(0.8) & Consultant (0.8) & Low(0.4) & Diploma(0.2) \\
\hline 16-20 Years(1.0) & 16-20 Years(1.0) & Principal (1.0) & $\begin{array}{c}\text { Very Low } \\
(0.2)\end{array}$ & \\
\hline
\end{tabular}

Table 3: $\quad$ Experts’ qualifications (attributes).

\begin{tabular}{|c|c|c|c|c|c|}
\hline $\begin{array}{c}\text { Expert } \\
\text { No. }\end{array}$ & $\begin{array}{l}\text { Q1: Years of } \\
\text { experience in } \\
\text { Sustainability } \\
\text { Projects }\end{array}$ & $\begin{array}{l}\text { Q2: Years in } \\
\text { Infrastructure } \\
\text { Projects }\end{array}$ & $\begin{array}{l}\text { Q3: Role } \\
\text { in } \\
\text { company }\end{array}$ & $\begin{array}{c}\text { Q4: } \\
\text { Diversity of } \\
\text { Experience }\end{array}$ & $\begin{array}{c}\text { Q5: } \\
\text { Academic } \\
\text { Record }\end{array}$ \\
\hline 1 & $16-20$ & $16-20$ & P.M. & V.High & Master \\
\hline 2 & $1-5$ & $1-5$ & S.P.E. & V.High & Bachelor \\
\hline 3 & $16-20$ & $16-20$ & P.M. & Average & Master \\
\hline 4 & $16-20$ & $16-20$ & P.M. & Average & Master \\
\hline 5 & $16-20$ & $16-20$ & S.P.E. & Average & Master \\
\hline 6 & $11-15$ & $11-15$ & S.P.E. & V .High & Bachelor \\
\hline 7 & $16-20$ & $16-20$ & P.M. & V.High & Bachelor \\
\hline 8 & $16-20$ & $16-20$ & P.M. & V .High & Master \\
\hline 9 & $11-15$ & $11-15$ & P.M. & V.High & Bachelor \\
\hline 10 & $6-10$ & $6-10$ & P.M. & Average & Master \\
\hline 11 & $6-10$ & $6-10$ & S.P.E. & Average & Bachelor \\
\hline 12 & $11-15$ & $11-15$ & P.M. & Average & Bachelor \\
\hline 13 & $11-15$ & $11-15$ & P.M. & Average & Bachelor \\
\hline 14 & $16-20$ & $16-20$ & S.P.E. & Average & Master \\
\hline 15 & $16-20$ & $16-20$ & P.M. & Average & Master \\
\hline 16 & $16-20$ & $16-20$ & P.M. & V .High & Bachelor \\
\hline 17 & $6-10$ & $6-10$ & P.M. & V .High & Master \\
\hline 18 & $6-10$ & $6-10$ & P.M. & V .High & Bachelor \\
\hline 19 & $6-10$ & $6-10$ & P.M. & V.High & Bachelor \\
\hline 20 & $1-5$ & $1-5$ & S.P.E. & V.High & Bachelor \\
\hline 21 & $1-5$ & $1-5$ & S.P.E. & V .High & Bachelor \\
\hline 22 & $1-5$ & $1-5$ & S.P.E. & V .High & Bachelor \\
\hline 23 & $16-20$ & $16-20$ & S.P.E. & V .High & Master \\
\hline 24 & $1-5$ & $1-5$ & S.P.E. & V .High & Bachelor \\
\hline 25 & $6-10$ & $6-10$ & P.M. & V.High & Bachelor \\
\hline 26 & $16-20$ & $16-20$ & P.M. & Average & Master \\
\hline 27 & $16-20$ & $16-20$ & P.M. & Average & Master \\
\hline 28 & $16-20$ & $16-20$ & S.P.E. & Average & Master \\
\hline 29 & $1-5$ & $1-5$ & S.P.E. & V .High & Bachelor \\
\hline 30 & $6-10$ & $6-10$ & P.M. & V.High & Bachelor \\
\hline
\end{tabular}


As illustrated in table 3, the P.M. stands for Project Manager, S.P.E. stands for Senior Project Engineer.

Table 4: $\quad$ Values of the eigenvectors of the AHP method.

\begin{tabular}{|c|c|c|c|c|c|c|c|}
\hline Criteria & $\mathbf{( Q 1 )}$ & $\mathbf{( Q 2 )}$ & $\mathbf{( Q 3 )}$ & $\mathbf{( Q 4 )}$ & $\mathbf{( Q 5 )}$ & $\begin{array}{c}\text { Nth Root of } \\
\text { Product }\end{array}$ & Eigenvector \\
\hline (Q1) & 4 & 4 & 3 & 4 & 5 & 3.949 & 0.202 \\
\hline (Q2) & 4 & 4 & 5 & 4 & 4 & 4.183 & 0.214 \\
\hline (Q3) & 3 & 4 & 4 & 5 & 3 & 3.728 & 0.191 \\
\hline (Q4) & 4 & 5 & 3 & 4 & 4 & 3.949 & 0.202 \\
\hline (Q5) & 4 & 3 & 5 & 4 & 3 & 3.728 & 0.191 \\
\hline \multicolumn{7}{|c|}{ Total } \\
\hline
\end{tabular}

The $\mathrm{n}^{\text {th }}$ roots are summed and that sum is used to normalize the eigenvector elements to add to 1 using Equation (1).

$$
\mathrm{rk}=\sum_{k=1}^{n} \mathrm{RK}
$$

where $r_{k}$ is an element of the eigenvector that represents the relative importance weight of a given criteria $(k), R_{K}$ is the $n^{\text {th }}$ root of product of each criteria, and $n$ is the number of criteria in the matrix. For example, the $5^{\text {th }}$ for the first row is $\mathrm{R}_{1}=3.949$, which is divided by the sum of the $\mathrm{n}^{\text {th }}$ root (19.537) to give 0.202 that is the first element in the eigenvector that denotes the relative importance weight $\left(r_{1}\right)$ of the criteria $\left(Q_{1}\right)$ years of experience in sustainability projects. After that, in order to compute the relative importance weight $\left(\mathrm{W}_{i}\right)$ of an expert $(i)$, the subjective weights $\left(g_{i}\right)$ of his or her attributes values are multiplied by the relative importance weights $\left(\mathrm{r}_{\mathrm{k}}\right)$ of each respective criterion and the sum of the products are normalized to determine $\mathrm{w}_{i}$, which ranges from 0 to 1 (Elbarkouky et al. [17]). For example, the importance weight $\left(\mathrm{W}_{i}\right)$ of a project manager $(0.6)$ who has a diversity of experience $H$ (0.8), has a Ph.D (1.0), has 20 years of experience in sustainability projects (1.0), and has 20 years of experience in infrastructure projects (1.0) could be computed using Equation (2).

$$
\mathrm{W}(i)=\sum \mathrm{g}(\mathrm{i}) * \mathrm{rk}
$$

where $g_{i}$ is the subjective weight of his individual attributes $(j)$ and $r_{k}$ is the relative importance weight of each respective criterion. Equation (3) illustrates the calculation of $\mathrm{w}_{\mathrm{i}}$ of that expert.

$$
\mathrm{W}_{\mathrm{i}}=1.0 * 0.202+1.0 * 0.214+0.6 * 0.191+0.8 * 0.202+1.0 * 0.191=0.924
$$

\subsection{Performing statistical analysis}

The statistical analysis of the experts' ratings determined the Mean, Median, Mode, Standard Deviation, Standard Error, and 95\% Confidence Range to advise on whether the opinions are converging or not. The 95\% Confidence Range is a type of interval estimate of a population parameter and is used to indicate the 
reliability of an estimate, where the 95\% Confidence Range reflects a significance level of 0.05 in the current study. The Standard Error was computed to measure the extent to which the means from different samples is expected to vary from the population mean, owing to the chance error in the sampling process, which was computed by dividing the Standard Deviation by the square root of $\mathrm{N}$, where $\mathrm{N}$ is the sample size. According to Montgomery [18], computing the Standard Error implies an acceptable agreement among experts. Abdelgawad [19] demonstrated that the calculated Standard Error is to be compared to 0.2 , as this value indicates a relatively precise point estimate of agreement among experts on the results (Shen et al. [20]).

\subsection{Assessing the Relative Importance Index (RII) for prioritization}

In this step, the Relative Importance Index (RII) was utilized to prioritize Critical Sustainability Indicators, based on the ranking of the experts (collected from step 2). This approach was applied because of its simplicity and ability to provide subjective and objective assessments of multiple factors (Elbarkouky et al. [17]). The average rating of the thirty experts (Table 3) who participated in the process of prioritizing critical sustainability indicators was computed. Equation (4) illustrates the RII computation.

$$
\mathrm{RII}=\frac{\sum_{i=1}^{n}(\mathrm{Wi} * \mathrm{Yi})}{\mathrm{Z}}
$$

where, $\mathrm{Wi}$ is the relative importance weights of experts participated in the process of decision-making, $y j$ is the rating score assigned to each sustainability indicator $(j$ ) by each expert ( $i$ ) on the Likert scale from 1 to 7 , and $z$ is the highest possible rating value of the Likert scale [16], which is 7 in this case. The RII value has a range between 0 to 1 ( 0 not inclusive), such that the higher its value, the more important the sustainability indicator is.

\subsection{Conducting a case study in Egypt (infrastructure water pipelines)}

Sustainability development plays a vital role in enhancing the understanding of people and developing there needed skills in order to be able to cope with the changes in the technological, economical, and social requirement. The Qualitative assessment framework was applied in this case study to be able to identify and qualify the critical sustainability Indicators affecting the infrastructure water pipelines projects in an Egypt Case study is conducted on ten water pipelines construction projects in greater Cairo. The thirty four sustainability indicators that have been previously identified in step 1 of the framework were introduced to thirty Egyptian experts to solicit their opinions regarding the linguistic criticality of indicator that would affect their projects objectives. The survey was conducted using the linguistic rating scales and questionnaire-based survey (step 2). The Relative Importance Weights of experts were determined using the Analytical Hierarchy Process (AHP) (step 3). The experts were carefully selected to possess different levels of experience, 
represent different sizes and maintain different experience levels in sustainability and infrastructure projects. The statistical Analysis was performed in (Step 4) in order to ensure the correctness of the data collected from experts, and to ensure that their final assessment is a result of common agreement. The Relative Importance Index (RII) was computed using equation (4) Step (5) to rank different sustainability indicators affecting the infrastructure water pipelines projects based on their consequence on projects objectives. Table 5 illustrates the case study projects, their descriptions, and their costs to the owner. Table 6 illustrates the Relative Importance Weights for the thirty experts who participated in the process of decision-making. Table 7 illustrates the computations of the Mean, Median, Mode, Standard Deviation, 95\% Confidence Range, Average Rating, Relative Importance Index (RII), and Rank of different sustainability indicators.

Table 5: $\quad$ Case study projects' descriptions.

\begin{tabular}{|c|c|c|c|}
\hline Project No. & Project Description & Project Cost & Project Location \\
\hline $\mathbf{1}$ & $\begin{array}{c}\text { Constructing 5 Km of G.R.P Water } \\
\text { Pipelines ranging from 800-1200mm. }\end{array}$ & $\begin{array}{c}\text { 10 Million } \\
\text { EGP. }\end{array}$ & El-Sheikh Zayed City \\
\hline $\mathbf{2}$ & $\begin{array}{c}\text { Constructing 20 Km of P.V.C Water } \\
\text { Pipelines ranging from 225-400mm. }\end{array}$ & $\begin{array}{c}12.5 \text { Million } \\
\text { EGP. }\end{array}$ & 6 October City \\
\hline $\mathbf{3}$ & $\begin{array}{c}\text { Constructing 35 Km of P.V.C Water } \\
\text { Pipelines sizing 225mm. }\end{array}$ & $\begin{array}{c}10 \text { Million } \\
\text { EGP. }\end{array}$ & 6 October City \\
\hline $\mathbf{4}$ & $\begin{array}{c}\text { Constructing 8 Km of G.R.P Water } \\
\text { Pipelines ranging from 800-1400mm. }\end{array}$ & $\begin{array}{c}13 \text { Million } \\
\text { EGP. }\end{array}$ & El-Sheikh Zayed City \\
\hline $\mathbf{5}$ & $\begin{array}{c}\text { Constructing 3 Km of G.R.P Water } \\
\text { Pipelines sizing 1400mm. }\end{array}$ & $\begin{array}{c}\text { 9 Million } \\
\text { EGP. }\end{array}$ & El-Sheikh Zayed City \\
\hline
\end{tabular}

Table 6: The relative importance weights of experts.

\begin{tabular}{|c|c|c|c|c|c|}
\hline $\begin{array}{c}\text { Expert } \\
\text { No. }\end{array}$ & $\begin{array}{l}\text { Importance } \\
\text { Weight }\left(\mathbf{W}_{i}\right)\end{array}$ & $\begin{array}{c}\text { Relative } \\
\text { Importance } \\
\text { Weight } \\
\text { Factor }\left(W_{i}\right)\end{array}$ & $\begin{array}{c}\text { Expert } \\
\text { No. }\end{array}$ & $\begin{array}{l}\text { Importance } \\
\text { Weight }\left(\mathbf{W}_{i}\right)\end{array}$ & $\begin{array}{c}\text { Relative } \\
\text { Importance } \\
\text { Weight } \\
\text { Factor }\left(W_{i}\right)\end{array}$ \\
\hline 1 & 0.8832 & 0.0417 & 16 & 0.8428 & 0.0398 \\
\hline 2 & 0.3667 & 0.0173 & 17 & 0.7168 & 0.0339 \\
\hline 3 & 0.8068 & 0.0381 & 18 & 0.6764 & 0.0319 \\
\hline 4 & 0.8068 & 0.0381 & 19 & 0.6764 & 0.0319 \\
\hline 5 & 0.7686 & 0.0363 & 20 & 0.555 & 0.0262 \\
\hline 6 & 0.8046 & 0.038 & 21 & 0.555 & 0.0262 \\
\hline 7 & 0.8046 & 0.038 & 22 & 0.555 & 0.0262 \\
\hline 8 & 0.8832 & 0.0417 & 23 & 0.8068 & 0.0381 \\
\hline 9 & 0.7596 & 0.0359 & 24 & 0.555 & 0.0262 \\
\hline 10 & 0.6404 & 0.0302 & 25 & 0.6764 & 0.0319 \\
\hline 11 & 0.5618 & 0.0265 & 26 & 0.8068 & 0.0381 \\
\hline 12 & 0.6832 & 0.0323 & 27 & 0.8068 & 0.0381 \\
\hline 13 & 0.6832 & 0.0323 & 28 & 0.7686 & 0.0363 \\
\hline 14 & 0.7686 & 0.0363 & 29 & 0.555 & 0.0262 \\
\hline 15 & 0.8068 & 0.0381 & 30 & 0.5932 & 0.028 \\
\hline \multicolumn{4}{|c|}{ Total } & 21.174 & 1.00 \\
\hline
\end{tabular}


Table 7: $\quad$ List of prioritized sustainability indicators.

\begin{tabular}{|c|c|c|c|c|c|c|c|c|}
\hline $\begin{array}{c}\text { Factors } \\
\text { ID }\end{array}$ & Mean & Median & Mode & $\begin{array}{l}\text { Standard } \\
\text { Deviation }\end{array}$ & $\begin{array}{c}\text { Standard } \\
\text { Error }\end{array}$ & $\begin{array}{c}95 \% \\
\text { Confidence } \\
\text { Range } \\
\end{array}$ & RII & Rank \\
\hline 1 & 6.867 & 7 & 7 & 0.346 & 0.107 & {$[7.476,6.258]$} & 0.981 & 1 \\
\hline 2 & 6.833 & 7 & 7 & 0.379 & 0.112 & {$[7.5,6.166]$} & 0.976 & 2 \\
\hline 4 & 6.8 & 7 & 7 & 0.407 & 0.116 & {$[7.517,6.083]$} & 0.971 & 3 \\
\hline 7 & 6.8 & 7 & 7 & 0.407 & 0.116 & {$[7.517,6.083]$} & 0.971 & 3 \\
\hline 5 & 6.767 & 7 & 7 & 0.43 & 0.12 & {$[7.524,6.01]$} & 0.967 & 4 \\
\hline 12 & 6.767 & 7 & 7 & 0.43 & 0.12 & {$[7.524,6.01]$} & 0.967 & 4 \\
\hline 18 & 6.633 & 7 & 7 & 0.615 & 0.143 & {$[7.716,5.55]$} & 0.948 & 5 \\
\hline 6 & 5.933 & 6 & 6 & 0.254 & 0.092 & {$[6.38,5.486]$} & 0.848 & 6 \\
\hline 19 & 5.933 & 6 & 6 & 0.254 & 0.092 & {$[6.38,5.486]$} & 0.848 & 6 \\
\hline 3 & 5.867 & 6 & 6 & 0.346 & 0.107 & {$[6.476,5.258]$} & 0.838 & 7 \\
\hline 13 & 5.8 & 6 & 6 & 0.61 & 0.143 & {$[6.874,4.726]$} & 0.829 & 8 \\
\hline 20 & 5.8 & 6 & 6 & 0.407 & 0.116 & {$[6.517,5.083]$} & 0.829 & 8 \\
\hline 8 & 5.733 & 6 & 6 & 0.45 & 0.122 & {$[6.525,4.941]$} & 0.819 & 9 \\
\hline 33 & 4.933 & 5 & 5 & 0.254 & 0.092 & {$[5.38,4.486]$} & 0.705 & 10 \\
\hline 14 & 4.9 & 5 & 5 & 0.305 & 0.101 & {$[5.437,4.363]$} & 0.7 & 11 \\
\hline 34 & 4.867 & 5 & 5 & 0.346 & 0.107 & {$[5.476,4.258]$} & 0.695 & 12 \\
\hline 15 & 4.8 & 5 & 5 & 0.407 & 0.116 & {$[5.517,4.083]$} & 0.686 & 13 \\
\hline 17 & 4.733 & 5 & 5 & 0.45 & 0.122 & {$[5.525,3.941]$} & 0.676 & 14 \\
\hline 9 & 4.667 & 5 & 5 & 0.479 & 0.126 & {$[5.511,3.823]$} & 0.667 & 15 \\
\hline 23 & 3.933 & 4 & 4 & 0.254 & 0.092 & {$[4.38,3.486]$} & 0.562 & 16 \\
\hline 16 & 3.9 & 4 & 4 & 0.305 & 0.101 & {$[4.437,3.363]$} & 0.557 & 17 \\
\hline 11 & 3.867 & 4 & 4 & 0.346 & 0.107 & {$[4.476,3.258]$} & 0.552 & 18 \\
\hline 10 & 3.8 & 4 & 4 & 0.407 & 0.116 & {$[4.517,3.083]$} & 0.543 & 19 \\
\hline 22 & 3.733 & 4 & 4 & 0.45 & 0.122 & {$[4.525,2.941]$} & 0.533 & 20 \\
\hline 29 & 3.1 & 3 & 3 & 0.403 & 0.116 & {$[3.81,2.39]$} & 0.443 & 21 \\
\hline 30 & 2.933 & 3 & 3 & 0.254 & 0.092 & {$[3.38,2.486]$} & 0.419 & 22 \\
\hline 28 & 2.867 & 3 & 3 & 0.346 & 0.107 & {$[3.476,2.258]$} & 0.41 & 23 \\
\hline 27 & 2.8 & 3 & 3 & 0.407 & 0.116 & {$[3.517,2.083]$} & 0.4 & 24 \\
\hline 21 & 2.133 & 2 & 2 & 0.507 & 0.13 & {$[3.026,1.24]$} & 0.305 & 25 \\
\hline 24 & 1.933 & 2 & 2 & 0.254 & 0.092 & {$[2.38,1.486]$} & 0.276 & 26 \\
\hline 25 & 1.867 & 2 & 2 & 0.346 & 0.107 & {$[2.476,1.258]$} & 0.267 & 26 \\
\hline 26 & 1.133 & 1 & 1 & 0.346 & 0.107 & {$[1.742,0.524]$} & 0.162 & 27 \\
\hline 31 & 1.067 & 1 & 1 & 0.254 & 0.092 & {$[1.514,0.62]$} & 0.152 & 28 \\
\hline 32 & 1.033 & 1 & 1 & 0.183 & 0.078 & {$[1.355,0.711]$} & 0.148 & 29 \\
\hline
\end{tabular}

\section{Conclusion}

A qualitative assessment framework was developed in this paper to prioritize different sustainability indicators affecting the construction of infrastructure water pipelines projects. The proposed framework was composed of six stages: Identifying critical sustainability indicators, creating linguistic scale to rate different critical indicators, and collecting experts' opinions, applying the Analytical Hierarchy Process (AHP) to determine experts' importance weights, performing statistical analysis, assessing the Relative Importance Index (RII) for prioritization, and conducting a case study in Egypt. Sustainability indicators affecting the construction of infrastructure water pipelines projects were identified using literature review and interviews with experts. A case study was conducted to demonstrate the validity of the qualitative assessment framework in 
identifying, and qualifying different indicators affecting the construction of infrastructure water pipelines projects in Egypt. The framework provided an improvement over previous qualitative models by incorporating the use of the Relative Importance Index (RII) to prioritize different indicators affecting the construction of infrastructure water pipelines projects, and determine the relative importance weights of experts participated in the process of decision-making. The framework improves over the previous models, which rely on the subjective assessment. In the future, the highly prioritized sustainability indicators will be introduced to another quantitative sustainability assessment model that quantify these indicators that is currently under preparation.

\section{References}

[1] Walsh, C., "Sustainable Design International. In co-operation with the Commission of the European Union, and the International Council for Research and Innovation in Building and Construction (CIB)" Adopted in Dublin, Ireland, on 6th November 1998. Updated in 2000.

[2] Fernández-Sánchez, G. and Rodríguez-López, F., "A methodology to identify sustainability indicators in construction project management Application to infrastructure projects in Spain”, Ecological Indicators, 10(6), 1193-1201, 2010.

[3] Zhang, L.L., Wang, L., Tian, J.X., "Study on sustainable construction management based on LCA." In International Conference on Construction on Real Estate Management, Toronto, Canada. 2008.

[4] Herrera, F., and Herrera-Viedma, E., "Linguistic decision analysis: steps for solving decision problems under linguistic information." Fuzzy Sets and Systems, 115(1), 67-82, 2000.

[5] Elbarkouky, M., and Fayek, A. R. "Fuzzy Similarity Consensus Model for Early Alignment of Construction Project Teams on the Extent of Their Roles and Responsibilities", Journal of Construction Engineering and Management, 137(6), 432-441, 2011.

[6] Herrera, F., Herrera-Viedma, E., and Verdegay, J., "A model of consensus in group decision making under linguistic assessments" Fuzzy Sets and Systems, 78(1), 73-87, 1996.

[7] Zabaal, N.Y "Risk Management of Pipeline Infrastructure Projects in Egypt", Master of Science Thesis, Structural Engineering Department, Cairo University, Egypt, 2007.

[8] Li, T., Zhang, H., Yuan, C., Liu, Z., Fan, C., “A PCA-based method for construction of composite sustainability indicators", The International Journal of Life Cycle Assessment, 17(5), 593-603, 2012.

[9] Kajikawa, Y., Inoue, T., Goh, T., "Analysis of building environment assessment frameworks and their implications for sustainability indicators", Sustainability Science, 6(2), 233-246, 2011.

[10] Munier, N., "Methodology to select a set of urban sustainability indicators to measure the state of the city, and performance assessment", Ecological Indicators, 11(5), 1020-1026, 2011. 
[11] Gómez-Limón, J. and Riesgo, L., "Alternative approaches to the construction of a composite indicator of agricultural sustainability: An application to irrigated agriculture in the Duero basin in Spain", Journal of Environmental Management, 90(11), 3345-3362, 2009.

[12] Xing, Y., Horner, R. Malcolm W, El-Haram, M., Bebbington, J., “A framework model for assessing sustainability impacts of urban development", Accounting forum, 33(3), 209-224, 2009.

[13] Azapagic, A., "Developing a framework for sustainable development indicators for the mining and minerals industry", Journal of Cleaner Production, 12(6), 639-662, 2004.

[14] Dasgupta, S. and Tam, E., "Indicators and framework for assessing sustainable infrastructure", Canadian Journal of Civil Engineering, 32(1), 30-39, 2005.

[15] San-Jose, J., Garrucho, I., Losada, R., Cuadrado, J., "A proposal for environmental indicators towards industrial building sustainable assessment", The International Journal of Sustainable Development and World Ecology, 14(2), 160-169, 2007.

[16] Saaty, T. L. Multi-criteria Decision Making: The Analytic Hierarchy Process. RWS Publications, Pittsburgh, PA, 1980.

[17] Elbarkouky, M. G., Ezzeldin, A. S., \& Elassaly, A. A multi-criteria decision-making (MCDM) framework for prioritizing damaged infrastructure and services facilities in Egypt using sustainability objectives. Proceedings, CSCE Annual Conference, 1st International Specialty Conference on Sustaining Public Infrastructure, Edmonton, Alberta, June 6-9, 2012, INF-S11-1011-1/11, 2012.

[18] Montgomery, D.C., Runger, G.C., and Hubele, N.F. Engineering Statistics, John Wiley \& Sons, New York, 1998.

[19] Abdelgawad, M. "Construction Schedule Delay Assessment in Joint Venture Projects: A Fuzzy Logic Method." Master of Science Thesis, Structural Engineering Department, Cairo University, Egypt, 2005.

[20] Shen, L.Y., Wu. G.W.C., and Ng, C.S.K. "Risk Assessment for Construction Joint Ventures in China." Journal of Construction Engineering and Management, 127(1), 76-81, 2001. 